\title{
Association of Maternal Hyperhomocysteinemia with Preeclampsia: A Hospital Based Case-Control Study
}

${ }^{1}$ Zoofishan Qureshi, ${ }^{1}$ Muhammad Ashraf Chaudhry, ${ }^{2}$ Seema Imdad,

${ }^{3}$ Tariq Mukhtar Farani, ${ }^{3}$ Ayesha Humayun

${ }^{I}$ Department of Community Medicine, CMH Lahore Medical College, Lahore

${ }^{2}$ Department of Nutrition and Dietetics, Institute of Public Health, Lahore

${ }^{3}$ Department of Surgery, CMH, Lahore

${ }^{2}$ Department of Community Medicine, Shaikh Zayed Medical Complex, Lahore

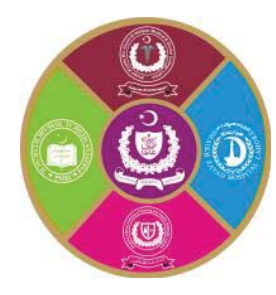

\begin{abstract}
Introduction: Preeclampsia is among the leading causes of feto-maternal morbidity and mortality throughout the world, especially in developing countries like Pakistan. The exact pathophysiology of preeclampsia is still unclear but recent research on homocysteine shows its important role. Aims \& Objectives: The aim of this study was to determine association of high serum homocysteine level with preeclampsia among antenatal women. Place and duration of study: Tertiary Care Hospitals of Lahore (Services, Lahore General Hospital and Sir Ganga Ram Hospitals) from $1^{\text {st }}$ January 2019 to $30^{\text {th }}$ June 2019. Material \& Methods: A matched case-control design was employed. Sixty-six diagnosed pre-eclamptic antenatal women were selected as cases and they were age and gestational weeks matched with sixty-six normotensive antenatal women as control, with a case to control ratio of 1:1. Serum homocysteine level in fasting sample was estimated by Enzyme linked immuno assay. Data was entered and analyzed through SPSS version 20. Results: The mean plasma homocysteine was significantly higher in cases $(16.05 \pm 2.25)$ as compared to controls $(9.44 \pm 2.83)$ with a $p$ value $<0.001$. Highly Significant statistical association was found between Hyperhomocysteinemia and Preeclampsia (p-value $<0.001$ with adjusted Odds Ratio of 4.72). Conclusion: Homocysteine levels a high in preeclamptic women as compared to normotensives showing that hyperhomocysteinemia is significantly associated with preeclampsia in antenatal women.
\end{abstract}

Key words: Hyperhomocystenemia, Preeclampsia, case-control study

\section{INTRODUCTION}

$\mathrm{P}$ morbidities and mortalities all over the world. Preeclampsia is a hypertensive disorder which is found in $3-10 \%$ of pregnancies worldwide. ${ }^{1}$ Prevalence ranges from $1.8 \%$ to $16.7 \%$ in developing countries. ${ }^{2,3,4}$

Preeclampsia ranks among priority public health issues in both advanced and less developed countries. It contributes significantly to maternal and perinatal morbidities and mortalities. Preeclampsia is a pregnancy specific disorder defined as the combination of high blood pressure, (hypertension), swelling (edema) and protein in the urine (albuminuria/proteinuria), developing after the 20th week of pregnancy. ${ }^{5}$

Preeclampsia has also been recognized as significant leading cause of maternal morbidity along with perinatal mortality and these women are more prone to have cardiovascular disease in later life ${ }^{6}$ Reduced blood flow to placenta causes ischemia/hypoxia which is proposed to trigger the release of a various placental factors that have marked effects on arterial pressure regulation and blood circulation. ${ }^{7}$ Preexisting hypertension, renal disease, strong family history of pre-eclampsia/eclampsia, systemic lupus erythematous and poor antenatal care are among predisposing/risk factors. ${ }^{8,9}$

It has also been proposed that the vasculature of pregnant mothers may show increased sensitivity to plasma level of homocysteine. ${ }^{10}$ Homocysteine (Hhcy) is a non-essential amino acid that contains sulphur and it is derived from demethylation of methionine. Methionine is an essential amino acid and it needs folate, vitamin B12 and B6 as coenzymes for its metabolism. Women developing severe preeclampsia tend to have higher plasma homocysteine levels as compared to women who 
have normal blood pressure throughout pregnancy. ${ }^{11}$ The vascular damage is accompanied by multi organ dysfunction with varying clinical features in advanced disease. ${ }^{12}$ Women with higher concentration of plasma homocysteine (hyperhomocysteinemia) levels during early pregnancy were found to have greater chance of developing preeclampsia and intrauterine growth restriction (IUGR). ${ }^{7,13,14,15}$ Recent literature based on large cohorts and many case-control studies reports significant association between homocysteine concentrations in maternal serum during early pregnancy and adverse pregnancy outcome and changes in placental vasculature. ${ }^{16,17}$ Current study was planned and conducted to identify the association as well as the strength of association between homocysteine levels and preeclampsia in local antenatal women of Lahore city.

\section{MATERIAL AND METHODS}

It was a matched case- control study conducted in Gynecology/Obstetric Outpatient Departments of Services Hospital Lahore, Lahore General Hospital and Sir Ganga Ram Hospitals from $1^{\text {st }}$ January 2019 to $15^{\text {th }}$ July 2019 . A total of 132 pregnant women were recruited comprising of 66 cases and 66 controls (keeping the cases to control ratio 1:1) through non-probability purposive sampling technique based on predetermined inclusion and exclusion criteria. Matching was done for age and period of gestation.

The sample size was calculated using the standard deviation (SD) of first group as 4, SD of second group 5, the mean homocysteine level among normotensive women taken as 17 , while in preeclamptic women as $13.50 .{ }^{18}$ The effect size in 0.77 while the probability of $\alpha$ error was set at 0.05 . The power of the study at 0.95 and the allocation ratio for cases and controls is taken as 1 . Including non-response, the minimum total sample size was estimated to be 100,50 in each minimum but we increased sample size to 66 in each group so as to enhance sample size a bit.

\section{Definition, source and selection of Cases:}

Pregnant women aged between 20 to 35 years at $\geq$ 20 weeks of gestation having confirmed preeclampsia by a gynecologist (with systolic blood pressure $\geq 140 \mathrm{mmHg}$ and diastolic blood pressure $\geq 90 \mathrm{mmHg}$ along with presence of albuminuria i-e1+ or more by dipstick method) were included in the study. These females were recruited through purposive sampling after taking written informed consent from antenatal OPDs of selected tertiary care hospitals of Lahore.

\section{Definition, source and selection of Controls:}

Pregnant women aged between 20 to 35 years at $\geq$ 20 weeks of gestation, normotensive with systolic blood pressure $\leq 120 \mathrm{mmHg}$ and diastolic blood pressure $\leq 80 \mathrm{mmHg}$ and no albumin in urine were enrolled as controls. These females were recruited through purposive sampling after taking written informed consent from antenatal OPDs of the same hospitals.

Females with following known conditions were excluded from the study; Eclampsia, cardiovascular disorder, Diabetes mellitus, renal failure, liver disease, multiple gestation, polyhydramnios and urinary tract infections.

Fasting blood samples were collected, centrifuged and stored for serum analysis. Five $\mathrm{ml}$ of blood was taken from median cubital vein under complete aseptic conditions. EDTA-plasma was used for estimation of homocysteine Enzyme Immunoassay (EIA). Samples were put in the ice packs before centrifugation. EDTA plasma samples were centrifuged or put on ice immediately after drawing. Samples were kept on ice for up to six hours prior to separation by centrifugation. Serum was separated by centrifuging at $3000 \mathrm{rpm}$ for 15 minutes and then stored at $2-8^{\circ} \mathrm{C}$ till further analysis.

Hyperhomocystenemia is an independent variable in this study while pre-eclampsia is a dependant variable. Hyperhomocystenemia is defined as plasma level of Homocysteine $\geq 15$ micro moles/L through ELISA kit. Age and gestational age were found to be confounding the relationship so they were matched among cases and control through pair matching.

\section{Statistical Analysis:}

Data was collected through questionnaire, which was entered in to computer using SPSS 20.0. For quantitative variables mean and standard deviation were calculated and for qualitative variables frequency and percentages were calculated. Independent sample $t$ test was used to find out mean difference of homocysteine levels in cases and controls. Chi-square test of significance was applied to find out association between categorical variables. The $\mathrm{p}$ - value, 95\% Confidence Interval and Odds Ratio was calculated to measure strength of association.

The study was carried out as per Helsinki declaration of human rights protection. Scientific and ethical review of this research was done by Department of Community Medicine CMH Lahore Medical College. 


\section{RESULTS}

The mean age in cases and controls was $26.76 \pm$ 5.82 years and $25.39 \pm 4.69$ years respectively. There was no statistically significant difference in mean age in both groups which showed that the age matching was appropriately done. The mean gestational period was $32.20 \pm 4.12$ weeks in Cases and $30.76 \pm 4.96$ weeks in Controls with no significant difference again due to appropriate matching of gestational age among cases and controls.

\begin{tabular}{|c|c|c|c|c|}
\hline & \multicolumn{2}{|c|}{ Study groups } & \multirow{2}{*}{$\begin{array}{c}\text { p- } \\
\text { value }\end{array}$} \\
\hline & & Cases & Controls & \\
\hline \multirow{5}{*}{$\begin{array}{c}\text { Educational } \\
\text { status }\end{array}$} & Illiterate & $11(16.7 \%)$ & $10(15.2 \%)$ & \multirow{5}{*}{0.019} \\
\hline & Primary & $34(51.5 \%)$ & $19(28.8 \%)$ & \\
\hline & Matric & $18(27.3 \%)$ & $26(39.4 \%)$ & \\
\hline & Intermediate & $3(4.5 \%)$ & $6(9.1 \%)$ & \\
\hline & $\begin{array}{l}\text { Graduation } \\
\text { and above }\end{array}$ & $0(0 \%)$ & $5(7.6 \%)$ & \\
\hline \multirow{2}{*}{$\begin{array}{c}\text { Monthly } \\
\text { income ( } R s)\end{array}$} & $<15000$ & $51(77.3 \%)$ & $46(69.7 \%)$ & \multirow{2}{*}{0.324} \\
\hline & $\geq 15000$ & $15(22.7 \%)$ & $20(30.3 \%)$ & \\
\hline \multirow{2}{*}{ Occupation } & Working & $1(1.5 \%)$ & $4(6.1 \%)$ & \multirow{2}{*}{0.171} \\
\hline & House wife & $65(98.5 \%)$ & $62(93.9 \%)$ & \\
\hline
\end{tabular}

Table-1: Comparison of Educational status, income and occupation among study population $(\mathrm{n}=132)$

Among Cases $51.5 \%$ had primary education, and among Controls $39.4 \%$ females were matriculated. Significant difference was seen in Cases and Controls as regards education level with low education level in Cases $(\mathrm{p}=0.019)$.

A total of $77.3 \%$ cases had monthly of income $<15000$ rupees while among Controls 69.7\% females had a monthly income of $<15000$ rupees. Majority of cases (98.5\%) and controls $93.9 \%$ were house wives. No significant difference was observed among cases and controls neither with regard to income nor with occupation status, ( $p$-value $=0.324$ and 0.171 respectively), (Table-1).

\begin{tabular}{|c|c|c|c|c|c|c|}
\hline & $\begin{array}{c}\text { Study } \\
\text { groups }\end{array}$ & Mean & S.D & Min. & Max. & $\begin{array}{c}\text { p- } \\
\text { value }\end{array}$ \\
\hline \multirow{3}{*}{$\begin{array}{c}\text { Plasma } \\
\text { homocysteine } \\
\text { level }\end{array}$} & $\begin{array}{c}\text { Case } \\
(\mathrm{n}=66)\end{array}$ & 16.05 & 5.25 & 7.90 & 28.00 & \multirow{3}{*}{$<0.001$} \\
\hline & $\begin{array}{c}\text { Control } \\
(\mathrm{n}=66)\end{array}$ & 9.44 & 2.83 & 6.00 & 17.90 & \\
\hline & $\begin{array}{c}\text { Total } \\
(\mathrm{n}=132)\end{array}$ & 12.74 & 5.35 & 6.00 & 28.00 & \\
\hline
\end{tabular}

Table-2: Comparison of mean plasma homocysteine level in cases and controls $(n=132)$
The mean plasma homocysteine was significantly higher in Cases $(16.05 \pm 5.25)$ as compared to Controls $(9.44 \pm 2.83), \mathrm{p}$-value $=0.001)($ Table-2) .

\begin{tabular}{|c|c|c|c|c|c|c|}
\hline *Hhcy & $\begin{array}{c}\text { Cases (pre- } \\
\text { eclamptic) } \\
n=66\end{array}$ & \begin{tabular}{|c|}
$\begin{array}{c}\text { Controls } \\
\text { (Normo- } \\
\text { tensive) } \\
n=66\end{array}$ \\
\end{tabular} & $\begin{array}{l}\text { Chi- } \\
\text { square } \\
\text { value }\end{array}$ & $\begin{array}{c}\text { p- } \\
\text { value }\end{array}$ & OR & $\begin{array}{c}95 \% \\
\text { C.I }\end{array}$ \\
\hline Yes & $34(52 \%)$ & $9(14 \%)$ & \multirow{2}{*}{21.56} & \multirow{2}{*}{0.001} & \multirow{2}{*}{6.72} & \multirow{2}{*}{$\begin{array}{l}2.86 \\
15.79\end{array}$} \\
\hline No & $32(48 \%)$ & $57(86 \%)$ & & & & \\
\hline
\end{tabular}

(*Hhcy= Hyperhomocysteinemia)

Table-3: Association between Preeclampsia and Hyperhomocysteinemia

Out of 66 Cases 52\% had Hhcy and $48 \%$ had normal plasma homocysteine level while 14\% Controls had Hhcy and $86 \%$ were with normal plasma homocysteine level and this difference was statistically highly significant $(\mathrm{p}=0.001$, Odds Ratio $=6.72$. $)($ Table-3) .

The odds of presence of elevated homocysteine levels are 6.72 times higher in preeclamptic female cases as compared to normotensive female controls.

\begin{tabular}{|c|c|c|c|c|c|c|c|c|c|}
\hline \multirow{2}{*}{ Variable } & \multirow{2}{*}{ Category } & \multicolumn{2}{|c|}{ Study group } & \multirow[t]{2}{*}{\begin{tabular}{|c|} 
p- \\
value
\end{tabular}} & \multirow{2}{*}{ OR } & \multirow[t]{2}{*}{$\beta$} & \multirow{2}{*}{\begin{tabular}{|c|}
$\mathbf{p}-$ \\
value
\end{tabular}} & \multirow{2}{*}{ AOR } & C-I \\
\hline & & Cases & controls & & & & & & \multirow{3}{*}{$\begin{array}{l}1.86 \\
11.85\end{array}$} \\
\hline \multirow{2}{*}{ *Hhcy } & Yes & $34(79 \%)$ & $9(20 \%)$ & \multirow[t]{2}{*}{0.001} & \multirow[t]{2}{*}{6.72} & \multirow[t]{2}{*}{1.55} & \multirow[t]{2}{*}{0.001} & \multirow[t]{2}{*}{4.73} & \\
\hline & No & $32(36 \%$ & $57(64 \%)$ & & & & & & \\
\hline \multirow{2}{*}{$\operatorname{Age}(y)$} & $\geq 30$ & $15(68 \%)$ & $7(32 \%)$ & \multirow{2}{*}{-0.062} & \multirow{2}{*}{2.47} & \multirow{2}{*}{0.001} & \multirow{2}{*}{0.999} & \multirow{2}{*}{0.99} & \multirow{2}{*}{$\begin{array}{c}0.32- \\
3.20\end{array}$} \\
\hline & $<30$ & $51(46 \%)$ & $59(54 \%)$ & & & & & & \\
\hline \multirow{2}{*}{ BMI } & $\geq 25$ & $46(63 \%)$ & $27(37 \%)$ & \multirow[b]{2}{*}{0.001} & \multirow[b]{2}{*}{3.32} & \multirow[b]{2}{*}{0.92} & \multirow[b]{2}{*}{0.021} & \multirow[b]{2}{*}{2.66} & \multirow{2}{*}{$\begin{array}{l}1.16- \\
6-10\end{array}$} \\
\hline & $<25$ & $20(34 \%)$ & $39(66 \%)$ & & & & & & \\
\hline \multirow{2}{*}{$\begin{array}{l}* \text { Edu. } \\
\text { status }\end{array}$} & illiterate & $11(52 \%)$ & $10(48 \%)$ & \multirow{2}{*}{0.812} & \multirow{2}{*}{1.12} & \multirow{2}{*}{0.12} & \multirow{2}{*}{0.820} & \multirow{2}{*}{1.13} & \multirow{2}{*}{$\mid \begin{array}{l}0.38 \\
03.31\end{array}$} \\
\hline & literate & $55(49 \%)$ & $56(51 \%)$ & & & & & & \\
\hline
\end{tabular}

Table-4: Logistic Regression model to determine Association between hyperhomocysteinemia and Preeclampsia $(\mathrm{n}=132)$.

*Hhcy=hyperhomocysteinemia.

$*$ Edu.status $=$ Education status

After controlling for age, education level and BMI, risk of developing preeclampsia is found to be 4.73 times higher in the subjects with hyperhomocysteinemia as compared to controls (Pvalue $=0.001) \quad($ Table-4), which shows that hyperhomocysteinemia is independent risk factor for preeclampsia. 


\section{DISCUSSION}

This research provides insight into strong association between hyperhomocysteinemia and syndrome of preeclampsia as seen in the current study. In this study, there was no difference in mean age and gestational age as they were matched and known hypertensives were excluded because evidence suggests that plasma homocysteine is positively associated with age as well as severe systolic hypertension. ${ }^{19}$ Results showed mean plasma homocysteine level significantly higher in cases $(16.05 \pm 2.25)$ as compared to controls $(9.44 \pm$ 2.83) with an unadjusted odds ratio of 6.72 and adjusted OR 4.73. The strength of association in our study is 4.73 times more in cases than in controls, which is quite high than found in previous literature. Similar relationship was found in many recent and old case control studies ${ }^{15,18}$ evaluating correlation and association of homocysteine levels in preeclamptics comparing with normotensives. In another study, raised total homocysteine serum levels were seen in women with severe preeclampsia as compared to mild preeclamptic females $(17.40 \pm 2.7$ vs $11.49 \pm 1.19 \mu \mathrm{mol} / 1, \mathrm{p}=0.001)$ and normal group $(17.40 \pm 2.7$ vs $6.38 \pm 0.3 \mu \mathrm{mol} / 1$. $(11.49 \pm 1.19$ vs $6.38 \pm 0.3) .^{2}$ Another case-control study, explored the association of Hcy in 3 groups of normotensive, pre-eclamptic and eclamptic women showing Hcy levels to be significantly increased in both case groups as compared to controls. ${ }^{11}$ Another Netherland based case-control study concluded threefold increased risk of developing preeclampsia with raised Hcy. ${ }^{20}$ Yet another study showed significantly higher serum homocysteine levels in women with severe preeclampsia than those with moderate and mild stage $(\mathrm{p}=0.025) .{ }^{14}$ The higher is homocysteine blood level more is the severity of preeclampsia. ${ }^{15}$

Supplementation of pregnant women with vitamin B6 and folic acid lowered homocysteine level and also helped to control preeclampsia and improve fetal growth suggested in an interventional study. ${ }^{21}$ Another study conducted in south India found out significant percentage of eclamptic patients had hyperhomocystenemia. ${ }^{22}$ Very strong association of higher homocysteine levels was shown to exist in etiology of preeclampsia as well as statistically significant association with severity of preeclampsia. ${ }^{13,14}$

Recent retrospective cohort study also supports the evidence that high Homocysteine concentration in the first trimester serves as an independent risk factor for development of severe preeclampsia but not a good marker for the gestational hypertension and mild preeclampsia. ${ }^{23}$

A systematic review published in 2005, based on previous researches concluded that there is lack of consistency of association, dose-response effect and biological plausibility of homocysteine in etiology of preeclampsia. ${ }^{24}$ The major cause of it is largely lack of consistency in data, particularly in our local literature. ${ }^{21}$

Now a recent Meta analysis published in 2019 to identify causal association between homocysteine and hypertension of 40173 individuals using Mendelian randomization concluded that there is a clear evidence on causal association between homocysteine concentration and the risk of developing hypertension. ${ }^{25}$ It is well evident from above discussion that many cited case control, cohort and experimental studies are supporting the link between Hcy and preeclampsia and the relationship between the preeclampsia but still more quality research is needed focusing on doseresponse relationship and biological plausibility to suggest causal link.

A number of diagnostic tests for biomarkers of preeclampsia are under exploration and many show restricted sensitivity and specificity. There is no single test which can accurately predict preeclampsia. Most of these tests have poor positive predictive values so a predictive model by identifying a number of factors and their effect can be helpful. ${ }^{14}$

Raised plasma Hcy levels are linked to an unhealthy lifestyle and faulty diet. Hcy levels may be improved by modification in lifestyle and dietary habits. The best approach is by educating people about the risks of raised Hcy levels, and empowering them to have a healthy lifestyle and diet. A healthy dietary pattern not only will lower Hcy levels but, will more notably boost health.

Current study has the limitation of not considering other potential links/ associations like with folate and B12 and the fact that case control studies can't rule out the effect of residual confounding.

In South Asian context, specifically in Pakistan, we can suggest more studies to see the racial differences in homocysteine levels among general population as well as antenatal women.

\section{CONCLUSION}

Study results conclude that higher antenatal blood concentration of homocysteine $(\geq$ micromole/L) is found to be five times higher in pre-eclamptic women as compared to normotensive pregnant women. 


\section{REFERENCES}

1. Organization WH. The World health report: 2005: make every mother and child count: World Health Organization; 2005.

2. Osungbade KO, Ige OK. Public health perspectives of preeclampsia in developing countries: implication for health system strengthening. Journal of pregnancy. 2011;2011.

3. Bilano VL, Ota E, Ganchimeg T, Mori R, Souza JP. Risk factors of pre-eclampsia/eclampsia and its adverse outcomes in low-and middle-income countries: a WHO secondary analysis. PloS one. 2014;9(3):e91198.

4. Shah N, Khan NH. Third delay of maternal mortality in a tertiary hospital. Rawal Med J. 2007; 32(Supplement 2):163-7.

5. Phipps E, Prasanna D, Brima W, Jim B. Preeclampsia: updates in pathogenesis, definitions, and guidelines. Clinical Journal of the American Society of Nephrology. 2016; 11(6):1102-13.

6. White WM, Turner ST, Bailey KR, Mosley Jr TH, Kardia SL, Wiste HJ, et al. Hypertension in pregnancy is associated with elevated homocysteine levels later in life. American journal of obstetrics and gynecology. 2013; 209(5):454. e1-e7.

7. Laskowska M, Oleszczuk J. Homocysteine in pregnancies complicated by preeclampsia with and without IUGR: a comparison with normotensive pregnant women with isolated IUGR and healthy pregnant women. Open Journal of Obstetrics and Gynecology. 2011; 1(4):191-6.

8. Shamsi U, Saleem S, Nishter N, Ameen A. Epidemiology and risk factors of preeclampsia; an overview of observational studies. Al Ameen J Med Sci. 2013; 6(4):292-300.

9. Ahmad S, Nazli R, Lutfullah G. Frequency of eclampsia and maternal complications in a tertiary care facility of Peshawar. Pak J Med Res. 2008; 47(4):79-82.

10. Noto R, Neri S, Noto Z, Cilio D, Abate G, Noto $\mathrm{P}$, et al. Hyperhomocysteinemia in preeclampsia is associated to higher risk pressure profiles. European review for medical and pharmacological sciences. 2003; 7:81-7.

11. Hasanzadeh M, Ayatollahi H, Farzadnia M, Ayati S, Khoob MK. Elevated plasma total homocysteine in preeclampsia. Saudi medical journal. 2008; 29(6):875.

12. Palei AC, Spradley FT, Warrington JP, George EM, Granger JP. Pathophysiology of hypertension in pre-eclampsia: a lesson in integrative physiology. Acta physiologica. 2013; 208(3):224-33.

13. Miglani S, Nautiyal R, Prakash A. Hyperhomocysteinemia in pre-eclampsia: is routine screening rational? International Journal of Reproduction, Contraception, Obstetrics and Gynecology. 2017; 6(4):1272.

14. Townsend R, O'Brien P, Khalil A. Current best practice in the management of hypertensive disorders in pregnancy. Integrated blood pressure control. 2016; 9:79.

15. Serrano NC, Quintero-Lesmes DC, BecerraBayona S, Guio E, Beltran M, Paez MC, et al. Association of pre-eclampsia risk with maternal levels of folate, homocysteine and vitamin B12 in Colombia: A case-control study. PloS one. 2018; 13(12): 0208137.

16. Maged AM, Saad H, Meshaal H, Salah E, Abdelaziz S, Omran E, et al. Maternal serum homocysteine and uterine artery Doppler as predictors of preeclampsia and poor placentation. Arch Gynecol Obstet. 2017; 296(3):475-82.

17. Nwogu CM, Okunade KS, Adenekan MA, Sekumade AI, John-Olabode S, Oluwole AA. Association between maternal serum homocysteine concentrations in early pregnancy and adverse pregnancy outcomes. Ann Afr Med. 2020; 19(2):113-8.

18. Ghike S, Jain S, Kumare B, Gupta M, Shembekar C. A study of serum homocysteine levels during normal pregnancy and preeclampsia. JSAFOG. 2011; 3(2):71-4.

19. Onyemelukwe OU, Maiha BB. Prevalence of hyperhomocysteinaemia, selected determinants and relation to hypertension severity in Northern-Nigerian hypertensives: the ABU homocysteine survey. Ghana Med J. 2020; 54(1):17-29.

20. Steegers-Theunissen RP, Van Iersel CA, Peer PG, Nelen WL, Steegers EA. Hyperhomocysteinemia, pregnancy complications, and the timing of investigation. Obstetrics \& Gynecology. 2004; 104(2):336-43.

21. Qureshi SB, Ahmad M, Qureshi PMA, Memon A, Qazi RA. Hyperhomocysteinaemia, vascular related pregnancy complications and the response to vitamin supplementation in pregnant women of Pakistan. JPMA The Journal of the Pakistan Medical Association. 2010; 60(9):741.

22. Arun M, Gopinath M, Nirmala C. Prevalence of hyperhomocysteinemia among preeclampsia patients. J Med Sci Clin Res.2017;5(04):21063-9

23. Sun F, Qian W, Zhang C, Fan J-X, Huang H-F. Correlation of maternal serum homocysteine in 
the first trimester with the development of gestational hypertension and preeclampsia. Medical science monitor: international medical journal of experimental and clinical research. 2017; 23:5396.

24. Mignini LE, Latthe PM, Villar J, Kilby MD, Carroli G, Khan KS. Mapping the theories of preeclampsia: the role of homocysteine. Obstetrics \& Gynecology. 2005; 105(2):411-25.

25. Fu L, Li YN, Luo D, Deng S, Wu B, Hu YQ. Evidence on the causal link between homocysteine and hypertension from a metaanalysis of 40173 individuals implementing Mendelian randomization.2019;21(12):1879-94.

\section{The Authors:}

Dr. Zoofishan Qureshi

Assistant Professor, Department of Community Medicine, CMH Lahore Medical College, Lahore.
Prof. Muhammad Ashraf Chaudhry Head, Department of Community Medicine, CMH Lahore Medical College, Lahore.

Prof. Seema Imdad

Department of Nutrition and Dietetics, Institute of Public Health, Lahore.

Dr. Tariq Mukhtar Farani

Assistant Professor,

Department of Surgery,

$\mathrm{CMH}$, Lahore.

Prof. Ayesha Humayun

HOD Public Health \& Community Medicine, Shaikh Zayed Medical Complex, Lahore.

\section{Corresponding Author:}

Dr. Zoofishan Qureshi

Assistant Professor,

Department of Community Medicine, CMH Lahore Medical College, Lahore.

E-mail: zimran195@gmail.com 